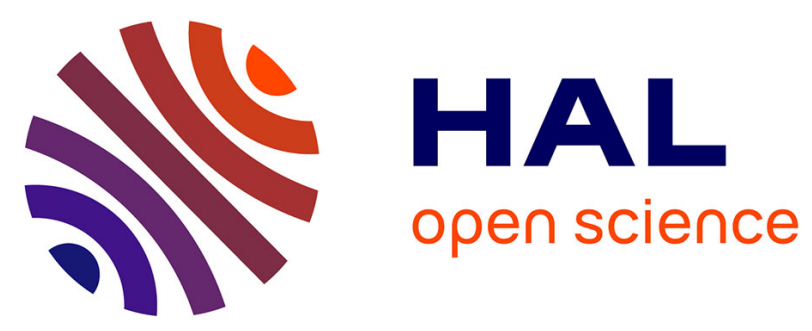

\title{
Volume charge carrier number fluctuations probed by low frequency noise measurements in InN layers
}

Geeta Rani Mutta, Jean-Marc Routoure, Bruno Guillet, Laurence Méchin, Javier Grandal, Sara Martin-Horcajo, Tomaso Brazzini, Fernando Calle, Miguel A. Sanchez-Garcia, Philippe Marie, et al.

\section{To cite this version:}

Geeta Rani Mutta, Jean-Marc Routoure, Bruno Guillet, Laurence Méchin, Javier Grandal, et al.. Volume charge carrier number fluctuations probed by low frequency noise measurements in InN layers. Applied Physics Letters, 2011, 98 (25), pp.252104-1-3. 10.1063/1.3601855 . hal-00976041

\section{HAL Id: hal-00976041 https://hal.science/hal-00976041}

Submitted on 9 Apr 2014

HAL is a multi-disciplinary open access archive for the deposit and dissemination of scientific research documents, whether they are published or not. The documents may come from teaching and research institutions in France or abroad, or from public or private research centers.
L'archive ouverte pluridisciplinaire HAL, est destinée au dépôt et à la diffusion de documents scientifiques de niveau recherche, publiés ou non, émanant des établissements d'enseignement et de recherche français ou étrangers, des laboratoires publics ou privés. 


\title{
Volume charge carrier number fluctuations probed by low frequency noise measurements in InN layers
}

\author{
Geeta Rani Mutta, ${ }^{1,2, a)}$ Jean Marc Routoure, ${ }^{2}$ Bruno Guillet, ${ }^{2}$ Laurence Méchin, ${ }^{2}$ \\ Javier Grandal, ${ }^{3}$ Sara Martin-Horcajo, ${ }^{3}$ Tommaso Brazzini, ${ }^{3}$ Fernando Calle, ${ }^{3}$ \\ Miguel A. Sánchez-García, ${ }^{3}$ Philippe Marie, ${ }^{1}$ and Pierre Ruterana ${ }^{1}$ \\ ${ }^{1}$ CIMAP, UMR 6252, CNRS-ENSICAEN-CEA-UCBN, 6, Boulevard du Maréchal Juin, \\ 14050 Caen Cedex, France \\ ${ }^{2}$ GREYC, UMR 6072, CNRS-ENSICAEN-UCBN, 6, Boulevard du Maréchal Juin, \\ 14050 Caen Cedex, France \\ ${ }^{3}$ Instituto de Sistemas Optoelectrónicos y Microtecnología and Dept. de Ingeniería Electrónica, \\ E.T.S.I. Telecomunicación, Universidad Politécnica de Madrid, Ciudad Universitaria, 28040 Madrid, Spain
}

(Received 16 March 2011; accepted 1 June 2011; published online 21 June 2011)

\begin{abstract}
Bulk conduction in molecular beam epitaxial InN layers has been confirmed using low frequency noise measurements versus temperature. A generation-recombination process has been identified at low temperatures $\leq 100 \mathrm{~K}$ and attributed to a trap with a discrete energy level in the band gap. The energy position of this trap has been determined to be around $52 \mathrm{meV}$ below the conduction band minimum. (C) 2011 American Institute of Physics. [doi:10.1063/1.3601855]
\end{abstract}

During the last decade indium nitride ( $\mathrm{InN})$ has been the subject of intense research, which led to the redefinition of its band gap from 1.89 to $0.69 \mathrm{eV}$, and pointed out its many interesting properties, such as the smallest electron effective mass, ${ }^{1}$ the largest mobility, ${ }^{2}$ and the highest peak and saturation electron drift velocities among the known semiconductors. ${ }^{1}$ Therefore, InN has emerged as a promising candidate for high speed electronic and optoelectronic applications up to terahertz frequencies. ${ }^{3}$ Despite these properties of InN, there are still many challenges for device fabrication which are related to material's quality, but also to the presence of an intrinsic charge accumulation at surfaces. ${ }^{4}$ In some cases, the presence of this electron accumulation layer may be of interest for sensor applications. ${ }^{5}$

There are many reports on surface charge accumulation in InN layers, including the measurements of sheet carrier density as a function of InN film thickness and capacitancevoltage $(\mathrm{C}-\mathrm{V})$ profiling. ${ }^{4}$ Photoemission measurements in InN with $\mathrm{Ti}$ or Au contacts showed that it was not possible to form Schottky contact, the authors concluded that the Fermi level was always located in the conduction band. ${ }^{6}$ The existence of an electron accumulation layer on clean InN (0001) surfaces has been confirmed by high resolution electron energy loss spectroscopy (HREELS) and x-ray photoemission spectroscopy. ${ }^{7}$ Angle-resolved photoemission spectroscopy was used to observe quantized energy levels in the surface electron accumulation layer on InN films grown by radio frequency plasma-assisted molecular beam epitaxy. ${ }^{8}$ Bhatta et $a l .^{9}$ reported the presence of charge accumulation on high pressure chemical vapor deposited $\mathrm{InN}$ layers by using HREELS and suggested that the excess surface electron accumulation presence in InN was not due to excess indium or In-In bonds. This is consistent with the pinning of the surface Fermi level in the conduction band. ${ }^{10}$ As was shown during the past few years, the surface Fermi energy in $\mathrm{InN}$ is pinned at $0.9 \mathrm{eV}$ above the bottom of the conduction band by donorlike surface defects, which creates an $n$-type accumu-

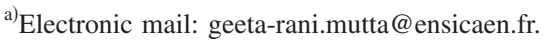

lation layer at the surface that seems unaffected by chemical or physical treatments. ${ }^{11}$ Obviously, the conductivity of this surface layer has to be considered in any investigation of the electrical properties of InN samples. Most recently, electrolyte based chemical $\mathrm{C}-\mathrm{V}$ measurements have been used to point out a net concentration of ionized acceptors below the $n$-type surface and demonstrated the possibility of $\operatorname{InN} \mathrm{p}$ doping using $\mathrm{Mg}$ acceptors. ${ }^{12}$

In this work, we have carried out low frequency noise (LFN) measurements in the 77-300 K temperature range on patterned InN films. In the following, we show that such measurements constitute a convenient tool to access the InN band gap, to investigate the conduction mechanisms and to relate them to the bulk and surface transport properties.

The investigated $\mathrm{InN}$ films were grown on c-plane sapphire substrate by plasma assisted molecular beam epitaxy (PA-MBE). The wafers consisted of the following multilayer structure: first, a commercial LUMILOG semi-insulating Ga polar GaN layer $(5 \mu \mathrm{m})$ grown by metalorganic vapor phase epitaxy on sapphire substrates served as a template. The PAMBE then started with the growth of a $90 \mathrm{~nm}$ thick GaN layer and the InN layer was grown on top with a nominal thickness of $345 \mathrm{~nm}$. Structural investigations show that such layers are of substantially good crystalline quality. ${ }^{13}$ In order to characterize the electric transport properties of these $\mathrm{InN}$ layers, a stack of metals Ti/Al/Ni/Au $(20 \mathrm{~nm} / 40 \mathrm{~nm} / 20$ $\mathrm{nm} / 80 \mathrm{~nm}$ ) was deposited using e-beam evaporation and annealed at $400{ }^{\circ} \mathrm{C}$ during $15 \mathrm{~min}$ in a $\mathrm{N}_{2}$ flow. Films were photolithographically patterned and processed by reactive ion etching to form transmission line method (TLM) structures. As shown in the inset of Fig. 1, each device was made of three TLM structures, of which we used TLM(a) constituted of a series of contact pads (area $94 \times 48 \mu \mathrm{m}^{2}$ ), with spacings of $38,57,114,170$, and $210 \mu \mathrm{m}$. The TLM patterns allowed us to determine both the contact and the InN layer sheet resistance. Direct current (dc) and noise measurements were performed using a four probe configuration setup in the 77-300 K temperature range with a Lakeshore TTP4 prober. The dc electrical resistivity and LFN measurements were carried out using a HP 4156B semiconductor parameter 


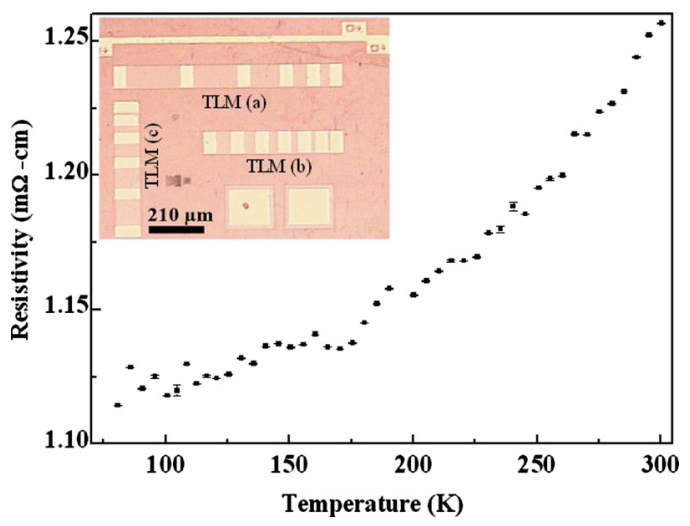

FIG. 1. (Color online) The electrical resistivity of the InN layer between 300 and $77 \mathrm{~K}$ increases with temperature above $100 \mathrm{~K}$, with a clear linear behavior above $130 \mathrm{~K}$, which is an indication of a metallic behavior. The inset is a schematic of the TLM patterns used for the measurements.

analyzer and a homemade low noise electronics read out associated with a 3562 A Dynamic Signal Analyzer, ${ }^{14}$ respectively. The home made amplifier uses junction field effect transistor based operational amplifiers with negligible input current noise thus enabling the measurement of a large range of resistance values. At $300 \mathrm{~K}$, the device LFN is close to one hundred times higher than the electronic readout noise for the lowest value of the current used in this work. At each temperature, the dc resistance $R$ and the LFN voltage spectral density $S v$ (from $10 \mathrm{~Hz}$ to $100 \mathrm{kHz}$ ) were measured for different dc bias currents.

The current-voltage (I-V) characteristics of InN TLM patterns were also measured at various temperatures. We had an Ohmic behavior for both the $\mathrm{InN}$ material and the metallic contacts in the whole temperature range. The contact and InN sheet resistance values were extracted from the measured resistance as a function of spacings between metallic pads. The measured contact resistance was always $10^{3}$ times smaller compared to the measured $\mathrm{InN}$ resistance. A decrease in the electrical resistivity with decreasing temperature down to approximately $130 \mathrm{~K}$ was observed for each characterized device, as illustrated for one device in Fig. 1. The temperature dependence of the resistance above $130 \mathrm{~K}$ showed, for all the devices, a positive temperature coefficient of about $7.70 \times 10^{-4} \mathrm{~K}^{-1}$ at $300 \mathrm{~K}$, which is in agreement with reported results in InN nanowires. ${ }^{15}$ This resistivity dependence with temperature is characteristic of a metal-like conductor in contrast to a nondegenerate semiconductor. ${ }^{15,16}$

In order to better understand the physical mechanisms behind the transport properties in our unintentional doped InN layer, noise measurements at different temperatures $\mathrm{T}$ have been carried out. LFN sources and especially 1/f noise sources are related to mobility fluctuations (charge carrier) in the bulk ${ }^{17}$ or number fluctuations which usually originates from the surface. ${ }^{18}$

Figure 2 shows two examples of typical noise spectral densities $S v$ as a function of frequency for different bias currents. These measurements were performed on a $94 \mu \mathrm{m}$ wide and $210 \mu \mathrm{m}$ long bridge at $300 \mathrm{~K}$ [Fig. 2(a)] and $77 \mathrm{~K}$ [Fig. 2(b)]. Before each noise measurement at different currents and temperatures, the resistance of the devices was systematically measured to check that it did not vary in the considered bias current range as a consequence of self heating.
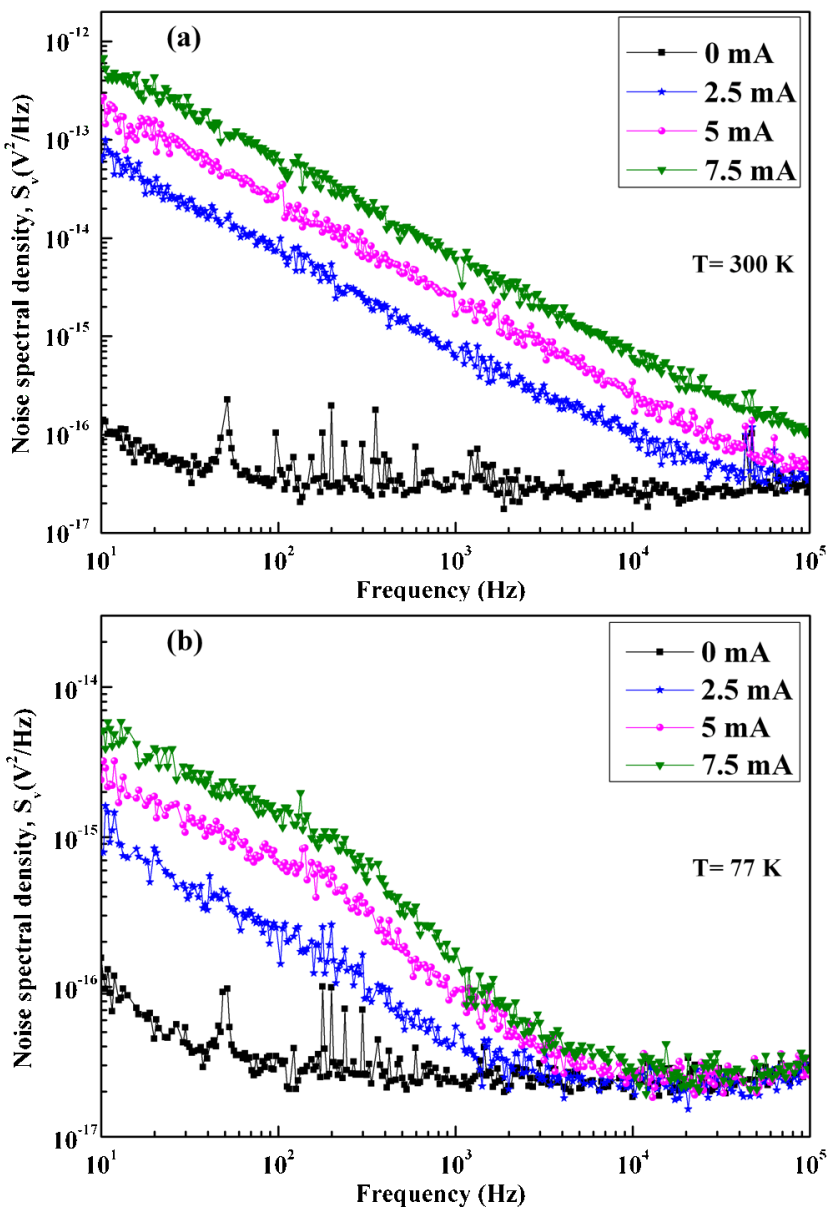

FIG. 2. (Color online) Voltage noise spectral densities measured for different dc bias currents: (a) $300 \mathrm{~K}(\mathrm{R} \sim 79 \Omega)$, the curves are dominated by the $1 / \mathrm{f}$ noise contribution with the usual slope of -1 . (b) Apart from the white and 1 /f noise contributions, at $77 \mathrm{~K}(\mathrm{R} \sim 71 \Omega)$, a Lorentzian contribution is now visible.

In Figs. 2(a) and 2(b), two different trends were observed above and below $100 \mathrm{~K}$. Above $100 \mathrm{~K}$ up to $300 \mathrm{~K}$ range, the spectra clearly consisted of following two parts: a 1/f noise contribution that depends on the bias current and frequency, and the white noise part which remains constant [Fig. 2(a)]. For each temperature the measured white noise level was in agreement with the dc electrical resistance according to $4 k_{B} T R$, where $k_{B}$ is the Boltzmann constant. The slope of the low frequency part was around -1 in the 10 $100 \mathrm{~Hz}$ frequency range, thus confirming the " $1 / \mathrm{f}$ " behavior. We checked the quadratic dependency of $S v$ versus the bias current (0 to $7.5 \mathrm{~mA}$ ), as expected in homogeneous samples. From this dependency, it was possible to calculate the figure of merit $\alpha \mu$ for the 1/f noise level ${ }^{19}$ which is the product of $\alpha$ the Hooge parameter and $\mu$ the carrier mobility at $300 \mathrm{~K}$. This figure of merit is around $100 \mathrm{~cm}^{2} \mathrm{~V}^{-1} \mathrm{~s}^{-1}$ for our sample at $300 \mathrm{~K}$ [corresponding to Fig. 2(a)] which is four orders of magnitude higher than those reported for poly $\mathrm{Si}$ or Ge for instance. ${ }^{20}$ This shows that even for MBE samples, as the growth parameters are critical $^{21}$ small deviations from optimal conditions may have a substantial impact on device performances as shown, in this instance, by the LFN measurements.

At lower temperatures $(\leq 100 \mathrm{~K})$, apart from the $1 / \mathrm{f}$ noise and white noise, a Lorentzian shape appears with a characteristic frequency $f_{c}$ and plateau levels that depend on 


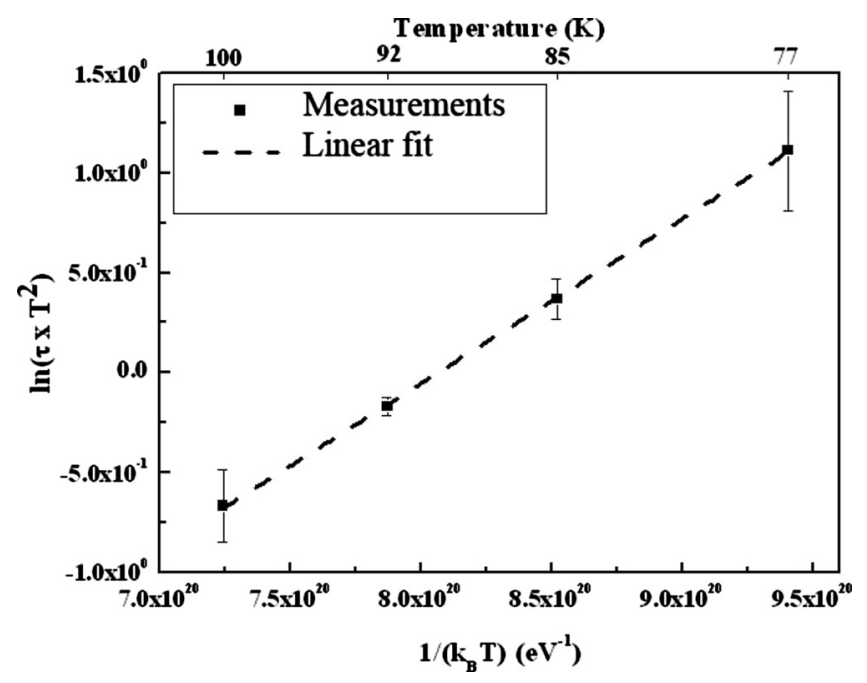

FIG. 3. The Arrhenius diagram obtained by plotting $\ln \left(\tau \times T^{2}\right)$ as a function of $1 /\left(k_{B} T\right)$, a trap energy level of $52 \mathrm{meV}$ below the conduction band minimum is obtained.

the temperature [Fig. 2(b)]. The characteristic frequency of the Lorentzian curves did not depend on the bias current and it decreased when the temperature was reduced. ${ }^{22}$ Conventionally, this Lorentzian profile is attributed to a generation recombination process due to a trap that has a discrete energy level in the band gap. A single relationship $\tau=1 / 2 \pi f_{c}$ exists between the time constant $\tau$ of the trap and the characteristic frequency of the Lorentzian. ${ }^{23}$ The Arrhenius diagram obtained by plotting $\ln \left(\tau \times \mathrm{T}^{2}\right)$ as a function of $1 /\left(k_{B} T\right)$ is shown in Fig. 3. For all the devices under study, the results were identical and showed a clear linear dependence. The energy level of the trap was deduced from the slope of the linear fit, its energy position being around $52 \mathrm{meV}$ below the conduction band minimum. As a consequence, these results can be interpreted as a transition from nondegenerated (below $100 \mathrm{~K}$ ) to a degenerated semiconductor. For temperature higher than $100 \mathrm{~K}$, only $1 / \mathrm{f}$ noise is observed and the electrical resistivity increases with the temperature: InN acts like a metallic conductor and no single trap generation recombination process can be observed. Below $100 \mathrm{~K}$, Lorentzians appear and electrical resistivity is more or less constant with the temperature: $\mathrm{InN}$ acts as a semiconductor. It was possible to probe a bulk trap thus indicating the part of the electrical conduction occurs in the bulk; a volume charge carrier number fluctuations was thus probed by the LFN measurements.

Apart from the Lorentzian behavior, an increase in one decade in the $1 / \mathrm{f}$ noise level with temperature from $77 \mathrm{~K}$ up to $300 \mathrm{~K}$ is observed. In order to explain this behavior, basic models for homogeneous sample were tested in order to distinguish between number and mobility fluctuations with either intrinsic or constant doping of free carriers. The most convincing one was the number fluctuations model with a constant doping of the free carriers. This model could explain the increase in the $1 / \mathrm{f}$ noise level with temperature indeed. As this model is often linked to surfaces, this fact is consistent with the presence of a free carrier accumulation layer at the surface reported by other techniques. ${ }^{4,6-10}$ As usual for 1/f noise interpretation, a more detailed analysis and model should be necessary to propose a clear conclusion on this fact.

In summary, LFN measurements were performed on MBE grown InN layers from $77 \mathrm{~K}$ up to $300 \mathrm{~K}$. The increase in the $1 / \mathrm{f}$ noise level with the temperature may be a confirmation of the electron accumulation layer at the surface which was already reported by other techniques. However, the Lorentzians observed at or below $100 \mathrm{~K}$ and the evolution of their characteristic frequencies with temperature are consistent with a generation-recombination mechanism due to a discrete trap level which has been determined at $52 \mathrm{meV}$ below the conduction band. These results show that with the present technique, it is possible to probe the part of the electrical conduction that takes place in the bulk of $\mathrm{InN}$ films.

The authors acknowledge the support by the EU under the Grant Agreement No. PITN-GA-2008-213238, Initial training network RAINBOW of the 7 RTD Framework.

${ }^{1}$ A. G. Bhuiyan, A. Hashimoto, and A. Yamamoto, J. Appl. Phys. 94, 2779 (2003).

${ }^{2}$ K. I. Lin, J. T. Tsai, T. S. Wang, J. S. Hwang, M. C. Chen, and G. C. Chi, Appl. Phys. Lett. 93, 262102 (2008).

${ }^{3}$ V. M. Polyakov and F. Schwierz, Appl. Phys. Lett. 88, 032101 (2006).

${ }^{4}$ H. Lu, W. J. Schaff, and L. F. Eastman, J. Appl. Phys. 96, 3577 (2004).

${ }^{5}$ H. Lu, W. J. Schaff, L. F. Eastman, and C. E. Stutz, Appl. Phys. Lett. 82, 1736 (2003).

${ }^{6}$ K. A. Rickert, A. B. Ellis, F. J. Himpsel, H. Lu, W. Schaff, J. M. Redwing, F. Dwikusuma, and T. F. Kuech, Appl. Phys. Lett. 82, 3254 (2003).

${ }^{7}$ T. D. Veal, I. Mahboob, L. F. J. Piper, C. F. McConville, H. Lu, and W. J. Schaff, J. Vac. Sci. Technol. B 22, 2175 (2004).

${ }^{8}$ L. Colakerol, T. D. Veal, H. K. Jeong, L. Plucinski, A. DeMasi, T. Learmonth, P. A. Glans, S. Wang, Y. Zhang, L. F. J. Piper, P. H. Jefferson, A. Federov, T. C. Chen, T. D. Moustakas, C. F. McConville, and K. E. Smith, Phys. Rev. Lett. 97, 237601 (2006).

${ }^{9}$ R. P. Bhatta, B. D. Thomas, M. Alevli, and N. Dietz, Surf. Sci. Lett. 601, L120 (2007).

${ }^{10} \mathrm{~W}$. Walukiewicz, Physica B 302-303, 123 (2001)

${ }^{11}$ I. Mahboob, T. D. Veal, C. F. McConville, H. Lu, and W. J. Schaff, Phys. Rev. Lett. 92, 036804 (2004)

${ }^{12}$ X. Wang, S. B. Che, Y. Ishitani, and A. Yoshikawa, Appl. Phys. Lett. 91, 242111 (2007).

${ }^{13}$ A. Vilalta-Clemente, G. R. Mutta, M. P. Chauvat, M. Morales, J. L. Doualan, P. Ruterana, J. Grandal, M. A. Sanchez-Garcia, F. Calle, E. Valcheva, and K. Kirilov, Phys. Status Solidi A 207, 1079 (2010).

${ }^{14}$ J. M. Routoure, D. Fadil, S. Flament, and L. Méchin, AIP Conf. Proc. 922, 419 (2007).

${ }^{15}$ C. Y. Chang, G. C. Chi, W. M. Wang, L. C. Chen, K. H. Chen, F. Ren, and S. J. Pearton, Appl. Phys. Lett. 87, 093112 (2005).

${ }^{16}$ T. Richter, H. Lüth, T. Schäpers, R. Meijers, K. Jeganathan, S. Estèvez Hernández, R. Calarco, and M. Marso, Nanotechnology 20, 405206 (2009).

${ }^{17}$ F. N. Hooge and L. K. J. Vandamme, Phys. Lett. A 66, 315 (1978).

${ }^{18}$ A. L. Mcwhorter, Ph.D. thesis, 1/f noise and related surface effects in germanium, Massachusetts Institute of Technology, 1955.

${ }^{19}$ C. Liang, G. Leroy, L. K. J. Vandamme, and J. L. Wojkiewicz, Synth. Met. 159, 1 (2009).

${ }^{20}$ L. K. J. Vandamme and H. J. Casier, Proceedings of the 34th ESSDERC, Leuven, edited by R. P. Mertens and C. L. Claeys (IEEE, Piscataway, NJ, 2004), p. 365

${ }^{21}$ C. S. Gallinat, G. Koblmüller, J. S. Brown, and J. S. Speck, J. Appl. Phys. 102, 064907 (2007).

${ }^{22}$ N. B. Lukyanchikova, Noise and Fluctuations Control in Electronic Devices, edited by A. Balandin (American Scientific, California, 2002), p. 201.

${ }^{23}$ V. Grassi, C. F. Colombo, and D. V. Camin, IEEE Trans. Electron Devices 48, 2899 (2001). 